\title{
Identification of improvised explosives residues using physical- chemical analytical methods under real conditions after an explosion
}

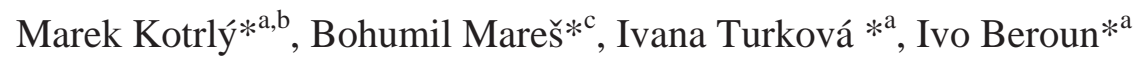 \\ ${ }^{a}$ Institute of Criminalistics Prague, Strojnická 27, POBox 62/KUP, 17089 Praha 7, Czech Republic; \\ ${ }^{\mathrm{b}}$ Charles University in Prague, Faculty of Science, Praha, Czech Republic, \\ ${ }^{\mathrm{C}}$ University of Pardubice Czech Republic.
}

\begin{abstract}
Within the analysis of cases relating to the use of explosives for crimes, we have experienced a shift from using industrial explosives towards substances made in amateur and illegal way. Availability of industrial explosives is increasingly limited to a narrow sphere of subjects with a relevant permission. Thus, on the part of perpetrators, terrorists, ever greater attention is paid to illegal production of explosives that are easily made from readily available raw materials. Another alarming fact is the availability of information found on the internet. Procedures of preparation are often very simple and do not require even a deeper professional knowledge. Explosive characteristics are not actually accessible for many of these substances (detonation velocity, sensitivity, working capacity, brisance, physical and chemical stability, etc.). Therefore, a project is being implemented, which on grounds of assessment of individual information available in literature and on the internet, aiming at choosing individual areas of potentially abusable substances (e.g. mixtures of nitric acid (98\%) with organic substances, mixtures nitromethane and tetranitromethane with organic substances, mixtures of chlorates and perchlorates of alkali metals with organic substances, chemically individual compounds of organic base type of perchloric acid, azides, fulminates, acetylides, picrates, styphnates of heavy metals, etc.). It is directed towards preparation of these explosives also in non-stoichiometric mixtures, conducting test explosives, determination of explosive characteristics (if they are unknown) and analysis of both primary phases and post-blast residues through available analytical techniques, such as gas and liquid chromatography with mass detection, FTIR, micro-Raman spectrometry, electron microscopy with microanalysis and Raman microspectrometry directly in SEM chamber for analysis at the level of individual microparticles. The received characteristics will be used to extend knowledge database for security forces.
\end{abstract}

Keywords: forensic science, forensic microscopy, electron microscopy, electron microanalysis, post-blast residues, improvised explosives

\section{INTRODUCTION}

To receive new analytical data of improvised explosives residues was motivated particularly by the pursuit of responding to a current development in the world where terroristic groups and movements in many states are being activated,which do not hesitate for enforcing their goals to use explosivesagainst various objects and human targets in a great extent. In a lot of cases, already known illegally made improvised explosives of a type of acetone peroxide, HMTD, mixtures of ammonium nitride with a fuel (DAP), etc. were used.

Within a statistical evaluation of cases concerning applying explosives to committing crimes on the territory of the Czech Republic from the past years, a significant shift from using industrially produced explosives to improvised explosives has been observed. This phenomenon is obviously caused by the fact that the availability of industrial explosives is in inland limited to a narrow sphere of subjects with strict criteria of selection (licensed trades). On the part of state, this field is also under supervision of the District Mining Offices. Thus, on the part of perpetrators ever greater attention is paid to the illicit production of explosives.These are easily made explosives from readily available raw materials, which are at the disposal on the market or in chemical labs. Another source for the production of explosives made in an amateur way are products of civil entertainment pyrotechnics or explosives delaborated from military

Detection and Sensing of Mines, Explosive Objects, and Obscured Targets XXI, edited by Steven S. Bishop, Jason C. Isaacs, Proc. of SPIE Vol. 9823, 98230S

(C) 2016 SPIE · CCC code: 0277-786X/16/\$18 · doi: 10.1117/12.2224216

Proc. of SPIE Vol. 982398230 S-1 
ammunition from World War II, which can be found abundantly in places of former military operations or from ammunition present in current and past military training areas.

The European Union indeed took steps to partly limit the distribution of some precursors such as a concentrated hydrogen peroxide, chlorates,perchlorates, etc. However, in reality, this limitation can be avoided, for example by founding a trade with a purchase of these substances based on the company registration number or by delaboration of pyrotechnic mixtures containing perchlorates from an entertainment pyrotechnics.

This raises the question of whether it would be possible to use less known explosivesdescribed in a specialized literature and on web pages with meeting the standard of a relatively easy improvised preparation. At the same time, this begs the question of the identification of their residues, or products recovered at the crime scene after an explosion, using contemporaryphysical-chemical analytical forensic methods.

\section{OVERVIEW OF THE CHOSEN CATEGORIES OF EXPLOSIVES MADE IN AN AMATEUR WAY}

The individual areas of potentiallyabusable substances suitable for the amateur improvised production of explosives were subsequently forecasted by a complex assessment of information that can be found at the internet and in a specialized literature.

Individual categories of explosives were selected with regard to the availability of raw materials usable for their manufacture and considering real possibilities of illegal manufacturers of explosives, i.e. technologies not requiring either a special equipment or a deeper professional knowledge. In this context, it is appropriate to state that it was proved through the literature search that the stated spectrum of substances in individual categories of explosives has never been dealt with at such a complex extent.

From a wide range of manufacturable improvised explosives, five categories of secondary explosives have been selected that are easily producible and at the same time their identification using physical-analytical methods has not been developedso far in a real environment.

a) The first category constitutes liquid explosives on the basis of mixtures of the concentrated nitric acid (98\%) with organic fuel (particularly aromatic nitro compounds, e.g. nitrobenzene,nitrotoluene, nitrophenol, dinitrotoluene, dinitrobenzene, etc.) Although nitric acid concentrated this way is not commonly available, it can be easily made by distillation of concentrated sulphuric acid with readily available alkali nitrates in a glass distillation apparatus.

b) The second category comprises explosives on the basis of perchloric acid and organic bases(e.g. ethylenediamine, phenylenediamine, aniline). Resulting compounds are solid perchlorates, for example aniline perchlorate, that of ethylediamine, guanidine, hydrazine, phenylenediamine, ect.

c) The third category is represented by mixed explosives on the basis of potassium chlorate, potassium perchlorate and ammonium perchlorate in a mixture with organic fuels (previously used explosives under the name of cheddites). These are heterogeneous mixtures of the mentioned oxidizers and fuels, such as vaseline, nitrobenzene, nitronaphthalene, nitrotoluene.

d) Liquid explosives on the basis of sensitized nitromethane (sensitizing admixtures, the type of aliphatic amines, e.g. ethylenediamine, dimethylamine). In this case, nitromethane is readily available as a component of fuels for modeller combustion engines and is available also in a pure form.

e) Mixed liquid explosives on the basis of tetranitromethane (TNM) and fuels (especially liquid aromatic hydrocarbons, such as benzene, toluene, xylene and the like. TNM is a substance that is usually unavailable, but it can be easily made from a highly concentrated nitric acid and acetic anhydride using an accelerator. These mixtures are characterized by a high detonation velocity and brisance comparable to most powerful known explosives (cyclonite, octogen). 
Concurrently withthe main categories of explosives will be monitored primary explosives - type and pyrotechnic explosive compositions -type. These are primary explosives of the type of lead azide, silver azide, mercury fulminate, silver fulminate, silver azetylide, copper acetylide, etc.Further, pyrotechnic compositions on the basis of inorganic oxidizers and fuels, e.g. lead monoxide-dioxide (so-called red-lead) - aluminium, potassium permanganate (so-called hypermangan) - aluminium, potassium perchlorate - aluminium, potassium chlorate - aluminium, etc. As fuels will be next used also magnesium, titanium and zircon.

\section{TECHNICAL IMPLEMENTATION OF EXPERIMENTS}

The experiments themselves are designed to simulate the procedure under real conditions at the crime scene after an explosion, e.g. booby trapped explosive system. During this experiment, an explosive charge of an explosive of a defined weight (e.g. $250 \mathrm{~g}$ ), suspended in the air, is set off by a detonator. Under it, in a given distance (for example $50 \mathrm{~cm}$ ), there is a detection stub made of a steel sheet with dimensions of $33 \times 33 \mathrm{~cm}$ located on the ground. After setting off the explosive charge, post-blast residues are removed from the stub, possibly post-blast products (by swabbing, vacuuming), or it is possibleto secure for further analysis thewhole stubs and subsequently to carry out the sampling in a laboratory environment e.g. by rinsing with a suitable solvent, by direct dry sampling, etc.

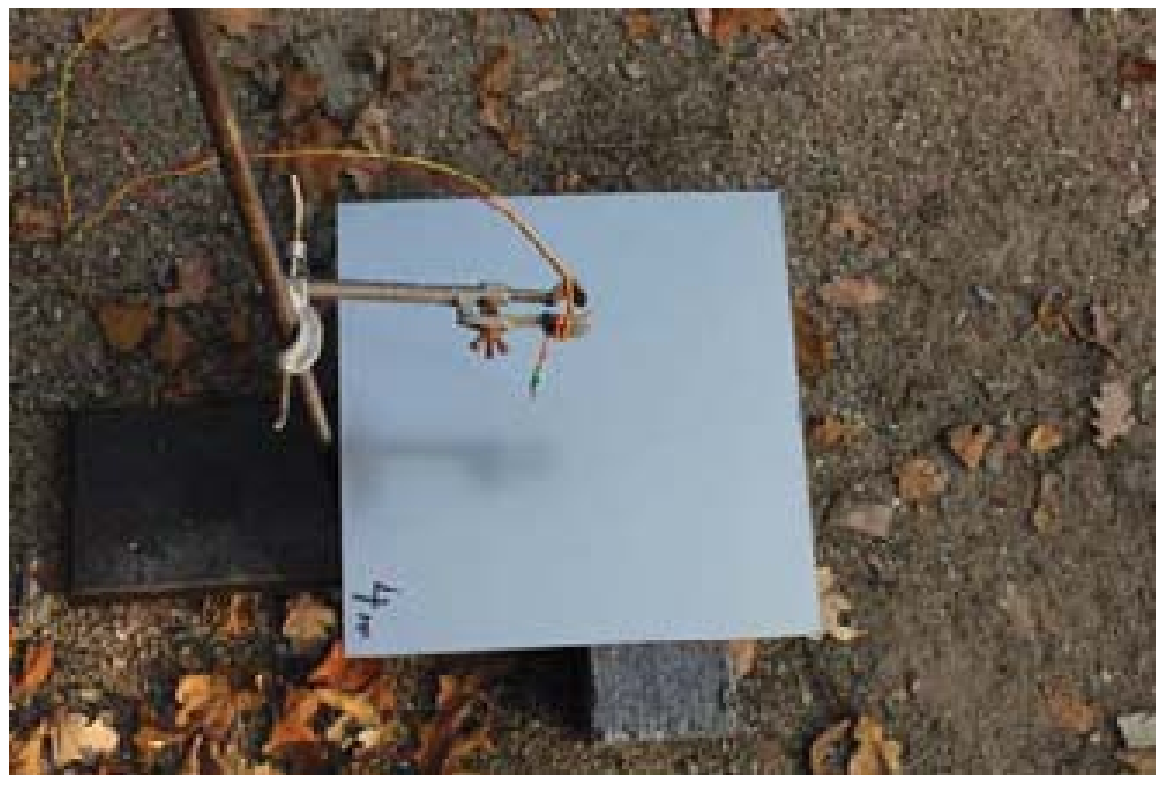

Figure 1. Experimental conditions of the first experiments with high explosives 


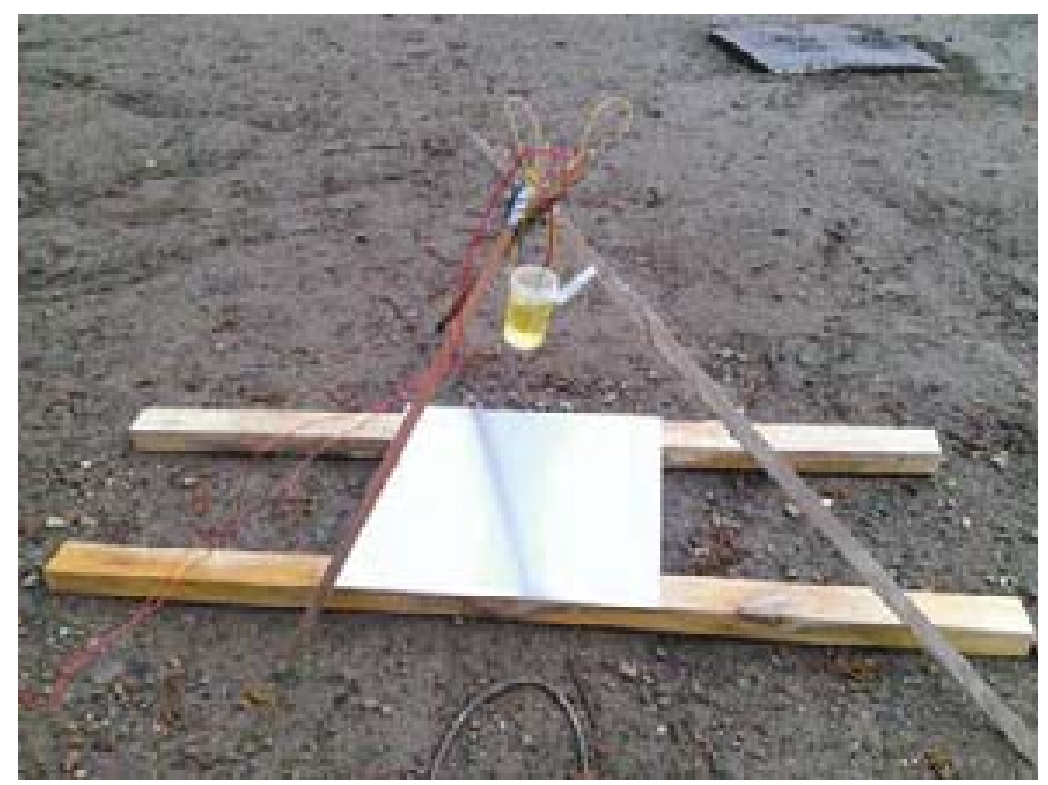

Figure 2. Experimental conditions of the first experiments with liquid explosives

\section{ANALYSIS OF RECOVERED SAMPLES}

Samples are further analysed to determine the presence of post-blast residues or products. The samples are analysed comprehensively both in terms of organic and inorganic contents.

a) Organic analysis

Following previous experience, the use of the two-stage instrumental sequence in the order - primary instrumental separation technique and secondary sensitive analytical detection seems to be an optimal system for a targeted analysis of post-blast residues.

As separation techniques will be applied methods of gas and liquid chromatography. Gas chromatography (GC) is used particularly to analyse volatile residues of explosives having a relatively high tension of vapours, characterized by a relatively high thermal stability (e.g. nitroglycerin, ethylene glycol dinitrate). Liquid chromatography (HPLC) is convenient for the use when analysing less volatile residues with a limited thermal stability (organic peroxides, amines). As a detection technique is employed the method of mass spectrometry(or from the mixture NB - nitric acid).

An initial series of test explosions with organic energetic materials was conducted in the first stage of the project. The selected manner of sampling of post-blast products and residues (teflonsquare swabs put in a borosilicate vial $16 \mathrm{ml}$ ), forms of analyte for analysis (SPME, extracts in acetone) and chosen devices (GC-MSD, GC-ECD) were tested in the test series of explosions the following mixtures with a concentrated nitric acid: nitrobenzene (NB)- nitric acid, polymethyl methacrylate (PMMA) - nitric acid, trinitroresorcinol (TNR) - nitric acid and 2, 4-dinitrotoluene (2,4-DNT) nitric acid. For the anticipated volatile products (NB, monomer or typical grafts from PMMA) was selected the SPME technique on the device GC-MSD. 

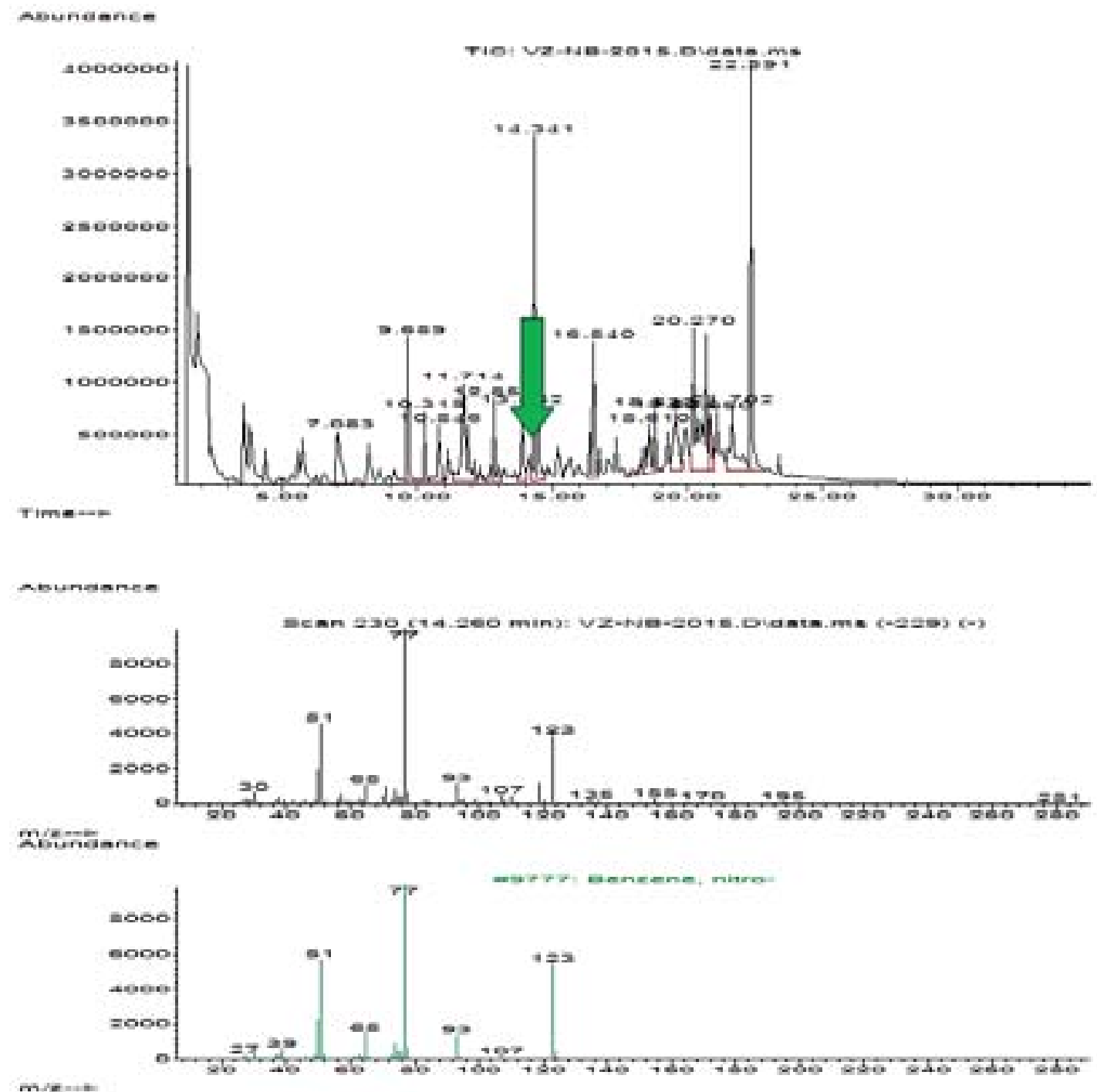

Figure 3. The residues of nitrobenzene (from the mixture NB - nitric acid) were positively identified - SPME technique on the device GC-MSD (HP 6890 GC System with 5973N MSD, column DB-5ms 30 m x $250 \mu \mathrm{m}$ x 0,25 $\mu \mathrm{m}$ )

In the case of the sample PMMA-nitric acid, characteristic volatile products reflecting retrospectively the structure of the original material PMMA were not identified. In the following phase, the remaining samples were extracted by acetoneand were analysed using GC-MSD and GC- $\mu$ ECD methods (Agilent Technologies 7890B GC System,columns RestekRtx-TNT $16 \mathrm{~m}$ x $530 \mu \mathrm{m} \times 1,5 \mu \mathrm{m}$ ). No residues of the original organic substances were found through these methods in the analytes (extracts), with the fact that thesubstance trinitroresorcine is not due to the chemical nature suitable for chromatographic determination (only the possibility of the occurrence of potential residues was verified). It was apparent that a big part of the original amount of TNR was not affected by the detonation, therefore, the additional method of infrared spectroscopy (FTIR) was applied with a positive result. Mixtures of nitric acid with NB, PMMA and 2,4 DNT during the explosion detonated, while the mixture with TNR only deflagrated. 
The technique of scanning electron microscopy in connection with EDS/WDS/microXRF analysis is employed to analyse samples containing inorganic components, the method allows not only a fundamental microanalysis of particles caught on the surfaces of the reference materials after explosions, but especially their distinction from ballast particles arising from contaminants occurring in the vicinity of the explosion. In relevant particles, it is possible to determine not only quantitative composition, but also visually identify their typical morphology and carry out an elemental mapping. In this case, the results of the analysis lead to a reliable identification of the originally used explosion.

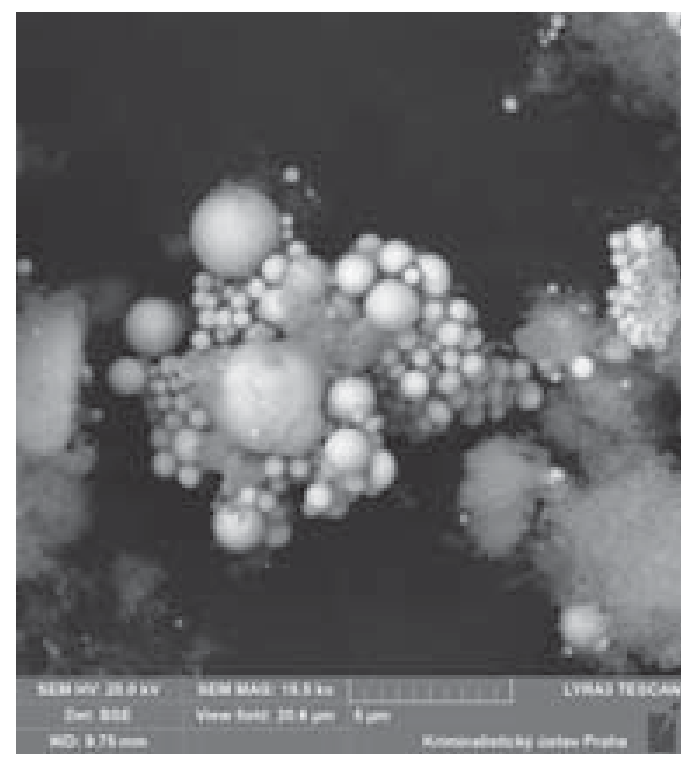

Figure 4. Study of the post-blast residues morphology of high explosives by SEM.

Furthermore, the researchof the inner structure of post-blast residues microparticles is carried out using the technique of focused ion beam that allowsdedusting material at an atomic/molecular level. The elemental mapping of individual sections and other microanalyses can be performed on completed sections, for example analysis of Raman spectra with various wave lengths, directly in the chamber of the electron microscope, mapping in Raman spectra, and the like.

There are currently devices facilitating Confocal Raman Imaging from microparticles, or their sections directly in the SEM chamber or SEM/FIB dual systems. The existing systems of Raman spectrometry combined with SEM have allowed only the imaging of individual spectra, without the option of direct observation of the scanned area and mapping. New systems are fully confocal, SEM keeps full functionality and scan range, very high resolution (for green laser resolution 360nm FWHM; $430 \mathrm{~nm}$ Rayleigh), it is fitted with high quality objective lens, enhances mapping through Raman spectrometry in a volume $250 \mu \mathrm{m}$ x $250 \mu \mathrm{m}$ x $250 \mu \mathrm{m}$ by piezo driven scanner (capacitive feedback

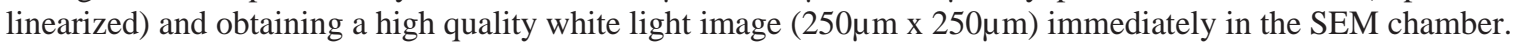

Currently a few wavelengths of excitation lasers are available for these devices - a blue laser (488 nm), a green laser (532 $\mathrm{nm})$ and a red one $(785 \mathrm{~nm})$. Several wavelengths are necessary for maximum versatility of the use and elimination of a possible flurescence with regard to a wide range of materials that can occur in post-blast residues.

A phase mapping in Raman spectra in the area 250 x 250 x250 micrometers using piezo-shift is feasible. It is also possible to combine a map with EDS elemental map, optical image from an integrated light microscope, or signals from SE and BSE SEM detectors. 3D confocal Raman imaging - non-destructive tomography for transparent materials is also practicable. 


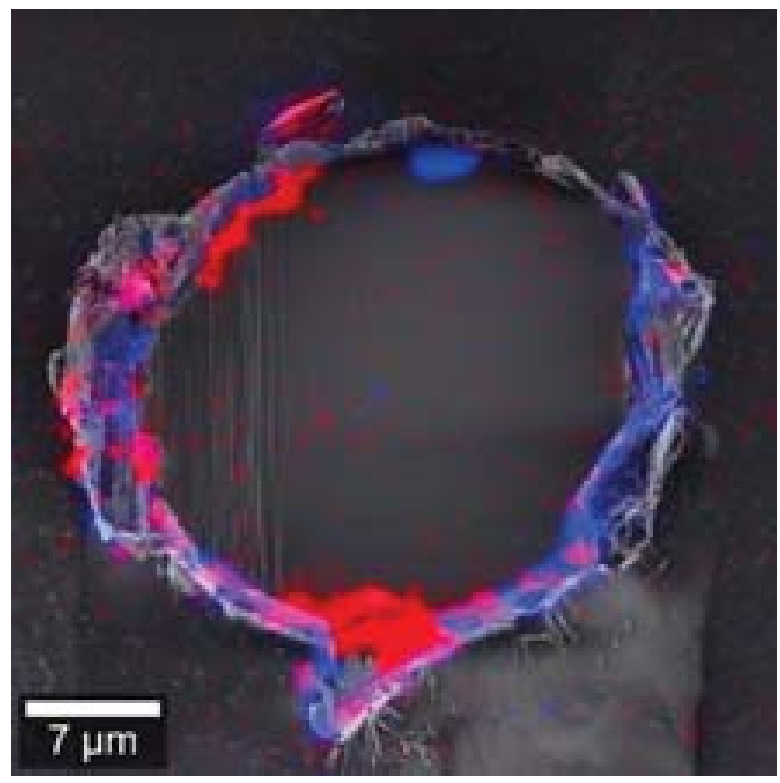

Figure 5. Phase mapping in the Raman spectrum at the cut of post-blast residues carried by FIB (overlayed SEM - in grey, and Raman phase mapping - color micrographs).

For direct phase analysis of post-blast residues is further used the technique of powder x-ray structural diffraction and microdiffraction allowing the direct phase analysis from the area of $100 \mu \mathrm{m}$. Samples for this technique are taken from detection stubs using microvacuums. The techniques allow the direct phase identification of a crystalline substance, even in mixtures. For the phase analysis, both international structural database ICDD and user databases are utilized that have been building for many years at a research workplace. 


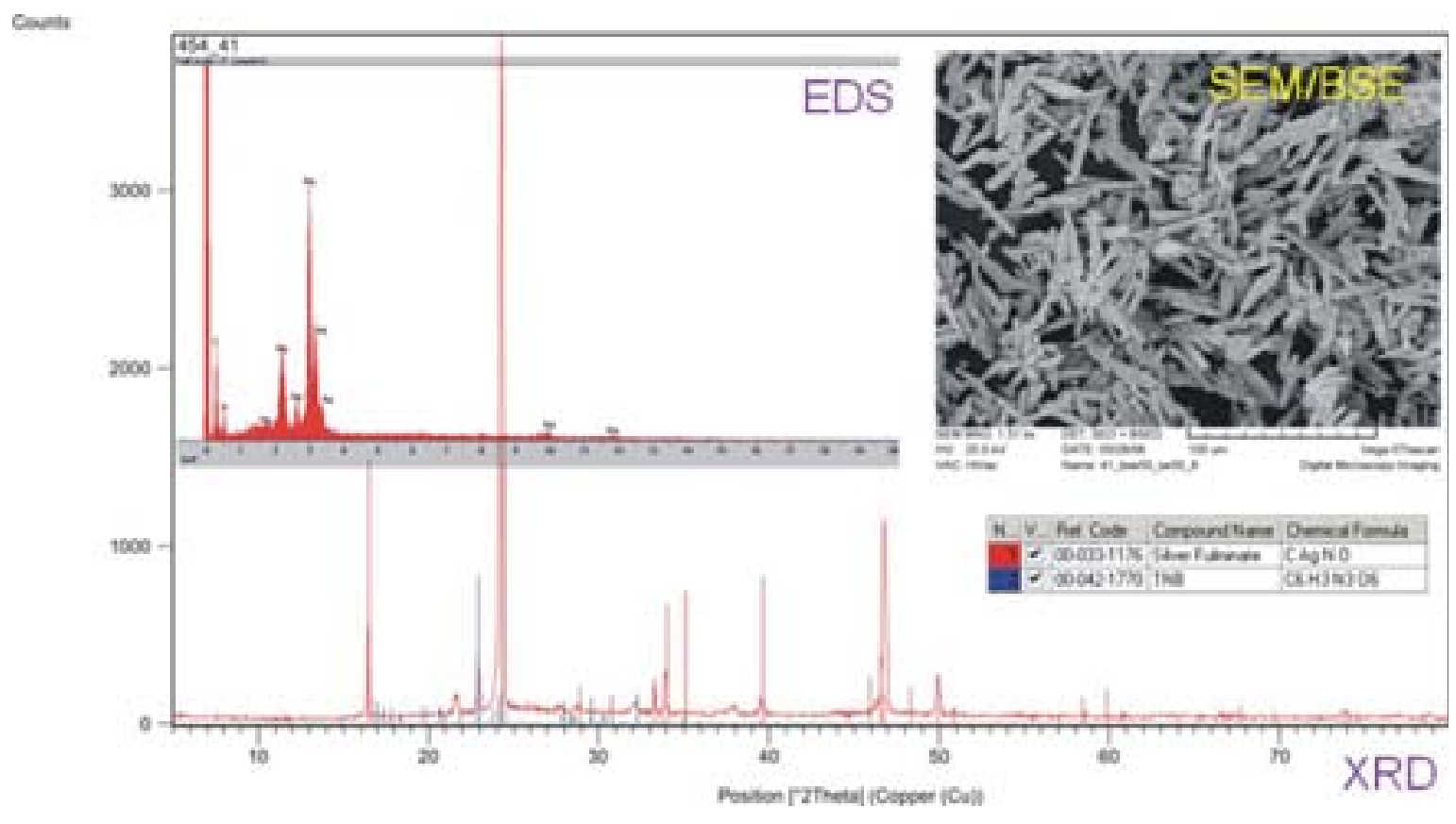

Figure 6. The example of the identification - complex analysis - SEM, EDS, microXRD.

\section{CONCLUSION}

The analysis of non-standard explosives and post-blast residues in forensic practice is a typical complex analysis using a wide range of analytical techniques. Combination of FTIR, Raman spectrometry, LC MS, GC MS, XRF, micro XRF and others are applied.

Furthermore, explosive characteristics if they are unknownare calculatedfor non-stoichiometric mixtures. All results will be entered into the database that will serve as the Expert Service of the Police of the Czech Republic and other specialized units.

\section{REFERENCES}

[1] Kotrlý M., Turková I.: Analysis of Nonstandard and Home-Made Explosives and Post-Blast Residues in Forensic Practice, Proc. SPIE 9073, Chemical, Biological, Radiological, Nuclear, and Explosives (CBRNE) Sensing XV, 90730U, pp.10, doi:10.1117/12.2050121, 2014.

[2] Kotrlý M., Turková I.: New Possibilities to Analyse Non-Standard Explosives and Post Blast Residues in Forensic Practice, In Tuan Vo-Dinh; Robert A. Lieberman; Günter G. Gauglitz: Advanced Environmental, Chemical, and Biological Sensing Technologies XII, Vol. 9486. pp. 948614-1 - 948614-11. ISBN:978-1-62841602-2, ISSN: 0277-786X, 2015.

[3] Jiruse J., et al.: FIB-SEM Instrument with Integrated Raman Spectroscopy for Correlative Microscopy, 990 991, Microsc. Microanal. 20 (Suppl 3), 2014. 


\section{ACKNOWLEDGMENTS}

Microanalytical methods at ICP were supported by projects of Ministry of the Interior VD20072010B15, VG20102015065, VF20112015016, VF20122015027, VI20152020004. 